\title{
HIV/AIDS Screening in the African Birthplace (Hospital in Kayes, Mali)
}

\author{
Mahamadou Diassana1, Ballan Macalou1, Sitapha Dembele1, A. Sidibe², M. Diallo², \\ Soumana Oumar Traore ${ }^{3}$, Cheickna Sylla4, Amadou Bocoum4, Ibrahima Teguete", \\ Youssouf Traore ${ }^{4}$
}

\author{
${ }^{1}$ Obstetrics and Gynecology Department at Fousseyni DAOU Hospital, Kayes, Mali \\ ${ }^{2}$ Kayes Reference Health Centre, Kayes, Mali \\ ${ }^{3}$ Reference Health Centre in Bamako Commune V, Bamako, Mali \\ ${ }^{4}$ Department of Obstetrics and Gynecology at Gabriel Toure University Hospital, Bamako, Mali \\ Email: mahamadoudiassana@gmail.com
}

How to cite this paper: Diassana, M. Macalou, B., Dembele, S., Sidibe, A., Diallo, M., Traore, S.O., Sylla, C., Bocoum, A., Teguete, I. and Traore, Y. (2021) HIV/AIDS Screening in the African Birthplace (Hospital in Kayes, Mali). Open Journal of $\mathrm{Ob}$ stetrics and Gynecology, 11, 279-287. https://doi.org/10.4236/ojog.2021.113027

Received: February 12, 2021

Accepted: March 15, 2021

Published: March 18, 2021

Copyright $\odot 2021$ by author(s) and Scientific Research Publishing Inc. This work is licensed under the Creative Commons Attribution International License (CC BY 4.0).

http://creativecommons.org/licenses/by/4.0/

\begin{abstract}
Purpose: The purpose of this study was to determine HIV prevalence among participants admitted to the delivery room and recent birth attendants. $\mathrm{Ma}$ terials and Methods: This was a descriptive, cross-sectional, analytical study, with a prospective collection from February 1, 2018 to January 31, 2019 at fousseyni Daou Hospital in Kayes, Mali. Results: During our study period, we recorded 4269 deliveries. HIV-positive patients known before labour accounted for $0.21 \%$. Four hundred and six participants received counselling/testing in the delivery room; of which 36 refused the test: $8.87 \%$ and 370 accepted or $91.13 \%$. Thirteen patients tested positive or $3.51 \%$. The $20-35$ age group was the most represented at $76.92 \%$. Positive patients tested received ARV treatment in the delivery room in $92.31 \%$ of cases; and 1 patient or $7.69 \%$ did not receive treatment for refusal. Vaginal delivery was the most common at $77 \%$, with caesarean section $23 \%$. Newborns had a good prognosis in their first weeks of life in $85 \%$; fetal lethality was observed in $15 \%$ of newborns including 1 case of fresh stillbirth and 1 case of pediatric deaths for neonatal suffering. Conclusion: Counselling and voluntary HIV/AIDS testing during labour and immediate postpartum can detect many pregnant women who escape screening during antenatal consultations.
\end{abstract}

\section{Keywords}

Screening, HIV/AIDS, Parturients, Delivery Room

\section{Introduction}

AIDS is a state of viro-induced immune deficiency [1]. In 2014, 36.9 million 
people were living with HIV, 70\% of whom were infected (WHO 2015 estimate) living in sub-Saharan Africa [2]. In 2010, 3.4 million infected people were children and more than $90 \%$ were infected vertically during pregnancy or breastfeeding. Mother-to-child transmission is one of the main modes of contamination [2]. This can be achieved in utero, per-partum, post partum and maternal breastfeeding [3]. Therefore, the means of preventing vertical transmission of HIV must be addressed in these three stages. For several years, there have been several methods of preventing mother-to-child transmission of HIV. Their evolution is linked not only to a better understanding of the risk factors for vertical HIV transmission, but also to the implementation of numerous clinical trials and protocols focusing on the use of antiretrovirals.

Although Africa has only $10 \%$ of the world's population, this is where $90 \%$ of HIV-infected "babies" are born, due to a combination of high prevalence of infection, high birth rates, lack of screening and adequate care for mothers. Mother-to-child transmission of HIV/AIDS is in the range of 30\% - 50\% [4].

In Mali, HIV testing is an integral part of prenatal consultation. All pregnant women received in NPC must be counselled on HIV/AIDS; but screening is done after informed consent [5]. In Mali, the HIV/AIDS pandemic remains an extremely serious public health and development problem, with women and children being the most vulnerable targets. In Mali, few studies have been devoted to HIV testing among parturients admitted to the delivery room, hence the initiation and interest of our study.

\section{Goals}

Purpose: The goal was to determine the prevalence of HIV/AIDS in the birthing room at Fousseini DAOU Hospital in Kayes, Mali.

\section{Materials and Methods}

This was a descriptive prospective, cross-sectional analytical study from February 1, 2018 to January 31, 2019, a 12-month period at Fousseyni Daou Hospital in Kayes.

Inclusion: Included in our study: parturients, recent births not screened for HIV during NPCs or who have been tested for more than 3 months and who accepted the HIV test after informed consent. Non-inclusion: Excluded from this work: participants who were screened for HIV in NPCs less than 3 months, who refused HIV testing after counselling.

For parturients received in the active phase of labour, counselling/screening was done in immediate postpartum. Post-test counselling was performed on all patients who accepted screening with immediate announcement of the result. Initial therapeutic education was done in all patients whose serological test returned positive. Confirmation and typing were requested from the laboratory and made later within a maximum of one week. All newborns of HIV-positive mothers received antiretroviral therapy (bitherapy) based on: Nevirapine syrup Zidovudine syrup. The newborns were referred to the paediatrics after they were 
taken into care in the delivery room.

Data analysis: Data collection was done by an individual survey sheet for each parturient screened.

The data entry was on Microsoft Word 10 and analyzed on Microsoft Excel 10, IBM SPSS 20 software. The khi2 test was used to compare proportions. The links are statistically significant if P-lt; 0.05 . The anonymity and confidentiality of those involved in the study were respected.

The Kayes region is located in western Mali. It covers an area of $120,760 \mathrm{~km}^{2}$ and has a population of 2,338,999. The Fousseyni DAOU Hospital in Kayes is a public hospital of 2 nd reference with a capacity of 160 beds. Difficulties encountered during this study: the failure of the 17-day screening test in the delivery room, the rupture of ARVs by 3 days for hiv-positive participants.

\section{Results}

\subsection{Epidemiological Aspects}

During our study period, we recorded 4269 deliveries. HIV-positive patients known before labour accounted for $0.21 \%$. Four hundred and six participants received counselling/testing in the delivery room; of which 36 refused the test: $8.87 \%$ and 370 accepted or $91.13 \%$. Thirteen patients tested positive or $3.51 \%$. Nine out of thirteen (69\%) patients want informed the procreator of their HIV status. The 20 - 35 age group was the most represented at $76.92 \%$. Out-of-school participants were the most represented with a frequency of $76.93 \%$. They had received information on HIV/AIDS at $98.1 \%$ and $57.85 \%$ had their information in health centres. The marital status of the tracked parturients is shown in Table 1.

Table 1. Epidemiological aspects of HIV-detected parturient from February 2018 to January 2019 at Fousseyni Daou Hospital in Kayes, Mali.

\begin{tabular}{cccccc}
\hline Age & HIV - & HIV+ & Profession & HIV- & HIV+ \\
\hline$\leq 19$ years old & $78(21.85 \%)$ & $2(15.39 \%)$ & Housewife & $295(82.63 \%)$ & $10(76.93 \%)$ \\
$20-35$ years old & $229(64.15 \%)$ & $10(76.92 \%)$ & Seller. shopkeeper & $29(8.12 \%)$ & $1(7.69 \%)$ \\
35 years old & $50(14.00 \%)$ & $1(7.69)$ & Official & $1(0.28 \%)$ & $1(7.69 \%)$ \\
Total & $357(100 \%)$ & $13(100)$ & Student/Student & $11(3.08 \%)$ & 0 \\
& & & Sex professional & $2(0.56 \%)$ & 0 \\
& & & Housekeeper & $19(5.32 \%)$ & $1(7.69 \%)$ \\
& & & Total & $357(100 \%)$ & $13(100 \%)$ \\
\hline
\end{tabular}

\begin{tabular}{ccc}
\hline Marital status & HIV - & HIV + \\
\hline Monogamous bride & $221(61.90 \%)$ & $3(23.08 \%)$ \\
Polygamous bride & $96(26.89 \%)$ & $9(69.23 \%)$ \\
Single & $30(8.40 \%)$ & $0(0 \%)$ \\
Divorce & $4(1.12 \%)$ & $0(0 \%)$ \\
Widow & $6(1.68 \%)$ & $1(7.69 \%)$ \\
Total & $357(100 \%)$ & $13(100 \%)$
\end{tabular}




\subsection{Clinical and Therapeutic Aspects}

Among the women screened and in the HIV group: $23.81 \%$ had performed antenatal consultations compared to $76.19 \%$ of women screened for HIV-had not performed antenatal consultations. Table 2 summarizes the situation of conducting prenatal consultations.

Several reasons were notified, this was the $c$ rainte of divorce in case of Positivity of the HIV test in $11.11 \%$, to take the advice of the partner for the completion of the test in $50 \%$. Some of them thought they were healthy at $5.56 \%$. This was the cause of the disease in $27.78 \%$ and without a well-founded reason in $5.55 \%$ (Table 3).

We noted the reactions of the participants to the result. Just over half of the participants accepted their status, $61.52 \%$, in $15.38 \%$ of crying, éni in $7.69 \%$ and diagnosis in $15.38 \%$. Patients' reactions to the HIV test result were reported in Table 4.

Table 2. Prenatal consultations for HIV-screened parturients from February 2018 to January 2019 at Fousseyni Daou Hospital in Kayes, Mali.

\begin{tabular}{ccc}
\hline The completion of the NPCs & HIV - & HIV + \\
\hline Yes & $85(23.81 \%)$ & $4(30.77 \%)$ \\
No & $272(76.19 \%)$ & $9(69.23 \%)$ \\
Total & $357(100 \%)$ & $13(100 \%)$ \\
\hline
\end{tabular}

$\mathrm{Khi}^{2}=0.33, \mathrm{p}=0.56$

Table 3. The main reasons for refusing to perform the HIV test for the parturients screened from February 2018 to January 2019 at Fousseyni Daou Hospital in Kayes, Mali.

\begin{tabular}{ccc}
\hline Reason for refusal & Effective & $\%$ \\
\hline Fear of divorce so positivity & 4 & 11.11 \\
Get the partner's opinion on the test & 18 & 50 \\
Think you're healthy & 2 & 5.56 \\
Fear of disease & 10 & 5.55 \\
No motive & 2 & 100 \\
Total & 36 & 58 \\
\hline
\end{tabular}

Table 4. Reactions of HIV-detected parturients to the positif result from February 2018 to January 2019 at Fousseyni Daou Hospital in Kayes, Mali.

\begin{tabular}{ccc}
\hline Reaction & Effective & $\%$ \\
\hline Accept & 8 & 61.52 \\
Denial & 1 & 7.69 \\
Cry & 2 & 15.38 \\
Refusal of diagnosis & 2 & 15.38 \\
Total & 13 & 100 \\
\hline
\end{tabular}


Depending on the timing of counselling and among those who tested positive, $61.54 \%$ of women were screened in the latency phase of labour versus $15.38 \%$ in the active phase and $23.08 \%$ in the immediate postpartum. For those with a negative result, $68.07 \%$ were episted in the latency phase, $23.18 \%$ in active phase and $8.40 \%$ in the immediate postpartum. The data on the timing of counselling are summarized in Table 5 .

Positive patients tested for antiretroviral therapy were given ten of ovir "lamuvudine" effavirenz (TDF-3TC-EFV) in the delivery room in $92.31 \%$ of cases. We recorded a case of success of $7.69 \%$. Vaginal delivery was the most common at $77 \%$, with caesarean section $23 \%$. Retroviral treatment and delivery are presented in Table 6 and Figure 1.

\subsection{Fetal Prognosis}

Newborns had a good prognosis in their first weeks of life in $85 \%$; fetal lethality was observed in $15 \%$ of newborns including 1 case of fresh stillbirth and 1 case of pediatric deaths for neonatal suffering.

Table 5. The time for counselling for women screened for HIV from February 2018 to January 2019 at Fousseyni Daou Hospital in Kayes, Mali.

\begin{tabular}{ccc}
\hline Time for counselling & HIV - & HIV ++ \\
\hline Latency & $243(68.07 \%)$ & $8(61.54 \%)$ \\
Active & $85(23.81 \%)$ & $2(15.38 \%$ \\
Immediate partum post & $30(8.40 \%)$ & $2(23.08 \%)$ \\
Total & $357(100 \%)$ & $13(100 \%)$ \\
\hline
\end{tabular}

Table 6. Antiretroviral treatment for HIV patients from February 2018 to January 2019 at Fousseyni Daou Hospital in Kayes, Mali.

\begin{tabular}{ccc}
\hline Molecules & Effective & Percentage \\
\hline TDF-3TC-EFV & 11 & $\mathbf{8 4 . 6 2}$ \\
No & 2 & 15.38 \\
Total & 13 & 100 \\
\hline
\end{tabular}

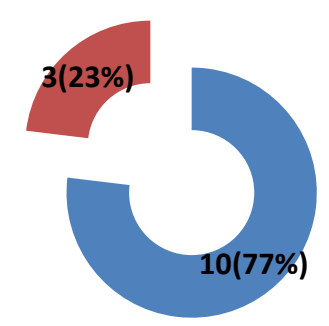

voie basse Césarienne

Figure 1. The mode of delivery of HIV-screened patients from February 2018 to January 2019 at Fousseyni Daou Hospital in Kayes, Mali. 
In our study, newborns weighing between 2500 - 3999 gr were $69.23 \%$ versus $37.77 \%$ of lower weight 2500 gr. We found 3 cases of prematurity or $23.08 \%$; hypotrophy is 7.69\%. Newborns had an Apgar score between 4 and 7 in $53.85 \%$ of cases; and $38.46 \%$ a score above 8 . We recorded a case of fresh stillbirths or 7.69\%. Anti-retroviral treatment has been initiated in newborns. This was a dual therapy done by nevirapine-zidovudine in $92.31 \%$ of cases.

Positive-tested mothers opted for artificial breastfeeding at $83.34 \%$ versus $8.33 \%$ for exclusive breastfeeding and $8.33 \%$ for mixed breastfeeding.

The neonatal prognosis is presented in Table 7.

\section{Discussion}

\subsection{Epidemiological Aspects}

In the literature, HIV/AIDS testing of parturients has been studied by authors. Various frequency rates have been reported. Dembélé B. [6] in its series in Mali reports a frequency $10 \%$ much lower than ours which is $3.51 \%$. The age range 20 - 35 years was $76.92 \%$. The parturients lived in a monogamous diet in $61.90 \%$. Among the positive participants, married women accounted for $92.31 \%$, of whom $75 \%$ lived in a polygamous regime. This result is superimposed with that of Dembélé B. [6] which reported $94.6 \%$ of married women and $74.3 \%$ of polygamous women.

The glare of divorce; fear of HIV/AIDS, stigmatization of people with HIV

Table 7. Antiretroviral treatment, breastfeeding and neonatal prognosis of newborns from HIV-positive patients from February 2018 to January 2019 at Fousseyni Daou Hospital in Kayes, Mali.

\begin{tabular}{|c|c|c|c|c|c|}
\hline Molecules & Effective & Percentage & Apgar & HIV- & VIH+ \\
\hline NVP-AZT & 12 & 92.31 & 0 & $6(1.68 \%)$ & $1(7.69 \%)$ \\
\hline No & 1 & 7.69 & $1-7$ & $24(6.72 \%)$ & $7(53.85 \%)$ \\
\hline \multirow[t]{2}{*}{ Total } & 13 & 100 & $\geq 8$ & 327 (91.60\%) & $5(38.46 \%)$ \\
\hline & & & Total & 357 (100\%) & $13(100 \%)$ \\
\hline Weight & HIV- & $\mathrm{HIV+}$ & Term & HIV- & $\mathrm{HIV+}$ \\
\hline$\leq 2500 \mathrm{~g}$ & $105(29.41 \%)$ & $4(30.77 \%)$ & Prematurity & $6(1.68 \%)$ & $3(23.08 \%)$ \\
\hline $2500-3999 \mathrm{~g}$ & $252(70.59 \%)$ & $9(69.23 \%)$ & Hypotrophy & $3(0.84 \%$ & $1(7.69 \%)$ \\
\hline Total & $357(100 \%)$ & 13 (100\%) & Normotrophy & $348(97.48 \%)$ & $9(69.23 \%)$ \\
\hline Term & HIV-tested & HIV & Breastfeeding & Effective & $\%$ \\
\hline Prematurity & $6(1.68 \%)$ & $3(23.08 \%)$ & Artificial & 10 & 83.34 \\
\hline Hypotrophy & $3(0.84 \%$ & $1(7.69 \%)$ & Mixed & 1 & 8.33 \\
\hline Normotrophy & $348(97.48 \%)$ & $9(69.23 \%$ & Maternal & 1 & 8.33 \\
\hline Total & $357(100 \%)$ & $13(100 \%)$ & Total & 12 & 100 \\
\hline
\end{tabular}


means that some patients refuse to take the HIV test. Despite the counselling, some refuse to take the test. The authors report different rates of HIV acceptance among participants and various reasons for refusing to test for HIV. In our series, counselling and screening were offered to all participants. Among them, we noted $91 \%$ acceptance rate and $9 \%$ refusal rate. The reasons given for refusing to take the test were in our series: fear of illness and fear of divorce in the event of a result positif, $27.78 \%$ and $11.11 \%$ respectively. Megni Gbeto-Obey et al. in Benin reported $74.8 \%$ acceptance rate [7]. The main reactions observed to the announcement of HIV were: resignation in $70.3 \%$, crying with $21.6 \%$ and mutism with $8.1 \%$. This result is consistent with that obtained by Ndayishimiyé J. in Be$\operatorname{nin}[8]$.

\subsection{Clinical and Therapeutic Aspects}

The period of prenatal consultations is ideal for HIV testing as part of the prevention of mother-to-child transmission. However, some pregnant people do not perform the test during this period. For these, screening in the birthing room or in the immediate postpartum are times to carry out the test. In our series, the participants who did not perform antenatal consultations accounted for $76.19 \%$. Positive participants received antiretroviral treatment in the delivery room in $92.31 \%$ of cases compared to $7.69 \%$ or 1 cases of refusal of treatment.

Of our pregnant women, $77 \%$ gave birth vaginally compared to $23 \%$ of caesarean section. These caesarean sections were indicated in obstetrics unrelated to the HIV status of the parturients. Dembélé B [6] found in his study, $89.2 \%$ of vaginal births versus $10.8 \%$ of caesarean section. The aftermath of immediate diapers was simple in $100 \%$ of cases.

\subsection{Newborn Diet and Neonatal Prognosis}

The neonatal prognosis depends on the birth weight, the hiv status of the mother, the implementation of antiretroviral treatment in the mother and the newborn, the presence or not of malformation of gestational age at birth. In our study, newborns weighing between 2500 - 3999 gr were $69.23 \%$ versus $37.77 \%$ of lower weight 2500 gr. Diouf A. et al. [9] in Dakar found an average birth weight of $2314 \mathrm{~g}$. Sombie I et al. [10] reported an average birth weight of $2831 \mathrm{~g}$ of newborns of HIV-positive mothers against a birth weight of $2896 \mathrm{~g}$ of newborns of HIV-negative mothers. We found 3 cases of prematurity or 23.08\%; hypotrophy is $7.69 \%$. Sombie et al. [10] found $8.1 \%$ of preterm infants from HIV-infected mothers compared to $3.6 \%$ of preterm infants of HIV-negative mothers. In Europe and the United States, the rate of preterm birth among infected women is about 10\% [11]. Newborns had an Apgar score between 4 and 7 in $53.85 \%$ of cases; and $38.46 \%$ a score above 8 . We recorded a case of fresh stillbirths or 7.69\%. Dembélé B. [6] found that $94.6 \%$ of newborns had an Apgar score between 8 - 10; and 2.7\% a score between 4 and 7. Anti-retroviral treatment has been initiated in newborns. This was a dual therapy done by nevirapine-zidovu- 
dine in $92.31 \%$ of cases. Positive-tested mothers opted for artificial breastfeeding at $83.34 \%$ versus $8.33 \%$ for exclusive breastfeeding and $8.33 \%$ for mixed breastfeeding. Dembélé B [6] reports in its series an artificial breastfeeding rate of $30.6 \%$.

Newborns had a good prognosis in their first weeks of life in $85 \%$; perinatal lethality was observed in $15 \%$ of newborns including 1 case of fresh stillbirth 1 case of pediatric death for neonatal suffering. Dembélé B. [6] observed 91.9\% of the newborns were alive at their first week of life, total perinatal lethality amounted to $8.1 \%$ or 3 cases: 1 macerated stillbirth and 2 newborn deaths in their first week of life.

\section{Conclusion}

Counselling and voluntary HIV/AIDS testing during labour and immediate postpartum can detect many pregnant women who escape screening during antenatal consultations.

\section{Authors' Contributions}

All the authors participated in the writing of the manuscript. They all approve the final version of the manuscript.

\section{Ethics Authorisation}

The ethics committee's authorization was found prior to the start of the study.

\section{Conflicts of Interest}

The authors state that they have no conflict of interest in this work.

\section{References}

[1] UNAIDS (2016) Backgrounder. 6, 4-5.

[2] UNAIDS AIDS (2015) 12, 5-9.

[3] Yapo Thomas, A.B.A., et al. (2016) Tropical Infectious Diseases. Alinéa Editions Plus, 580-625. http://www.infectiologie.com/

[4] UNAIDS/WHO (1999) Prevention of Mother-to-Child Transmission of HIV: Strategic Options. Geneva.

[5] (2016) Standards and Protocols for the Management of Antiretroviral HIV and AIDS. HCNLS, 124.

[6] Dembélé, B. (2010) HIV Testing in the Delivery Room at the Maternity Ward of the V Commune Reference Health Centre from February 2009 to January 2010[Mali].

[7] Third SAGO Congress (2002) Conference and Communication Book. Benin.

[8] Ndayishimiyé, J. (2004) Evaluation of the Quality of Prevention of Mother-to-Child Transmission of HIV during Birth at HOMEL. Public Health Memory: Cotonou IRSP.

[9] Diouf, A., Kebe, F., Faye, E., et al. (1996) HIV Infection in Pregnant Women in Dakar, Senegal. Jr Gynecol Obstet Biol Reprod, 23, 283-287.

[10] Sombie, I., Nacro, B., Tiendrebeogo, S., Dao, B., Carloux, M., Meda, N., et al. (1999) 
Maternal Infection and Anthropometric Parameters of the Child at Birth in Burkina Faso. Health Book, 9, 11.

[11] Mandelbrot, L. (1999) Pregnancy Is Particularly Special for HIV-Positive Pregnant Women. The Gynecologist's Letter, 243, 20-25. 